\title{
Presentation of the volume
}

\author{
Gabriela Pană Dindelegan* \\ Faculty of Letters, University of Bucharest, Str. Edgar Quinet 5-7, Sector 1, 010017 Bucharest, Romania \\ "Iorgu Iordan - Al. Rosetti" Institute of Linguistics, Calea 13 Septembrie 13, 050711 Bucharest, Romania
}

The $6^{\text {th }}$ issue of the journal "Diacronia" (6/2017) includes 12 papers covering topics on the diachronic grammar of Romanian, written by the members of the Department of Grammar of the "Iorgu Iordan Al. Rosetti" Institute of Linguistics of the Romanian Academy, Bucharest. Most of the studies address diachronic morphology, diachronic syntax or morpho-syntax issues and one of the papers deals with word formation and its relation to derivational morphology. These investigations are in line with older research topics developed in Department of Grammar (see the volume The Syntax of Old Romanian (sor), Oxford University Press, 2016, 680 p.) on the one hand, and, on the other, they bring to the fore partial results of an extensive work in progress on the diachronic morphology of Romanian.

A common characteristic of the articles included in the current issue is that they are based on corpus research. The authors employ a rich and diversified corpus of old Romanian (1521-1780), which was also used for SOR, using the same system of quoting (the acronym is followed by the year when the text was written/published; for example: $\mathrm{CC}^{2} .1581$, Po.1582, A.1620, AD.1722-5). Another common feature is related to the contents of the papers, as there are numerous ideas and concepts circulating in more than one article (i.e., the existence of grammaticalization stages and of incomplete grammaticalization processes, the lexical plural, the concepts of plurifunctionality, ambiguity/syncretism and the disambiguation mechanism, diachronic vs. synchronic variation, syntheticity vs. analicity, etc.).

The main goals of this thematic issue are:

(i) the presentation of the origin, chronology and localization, and the diachronic changes of the phenomena investigated;

(ii) the analysis of the syntactic and morpho-syntactic values of different formatives and the disambiguation mechanisms responsible for certain syncretic forms in old Romanian;

(iii) the examination of the different hypotheses and stages of the grammaticalization process;

(iv) the analysis of the structural and inflectional features of the old language, underlying the (partially) new results with respect to the data in the previous literature;

(v) emphasizing the wide interest in diachronic variation (formal, structural, related to word order or to functional values), characterising unstable linguistic domains, which anticipate important linguistic changes.

This issue also includes the philological edition of a fragment from an old text, carried out by Alexandru Nicolae. The author aims to re-edit an extremely significant text of the history of the Romanian linguistics, which belongs to B.P. Hasdeu, entitled Principie de linguistică 'Principles of linguistics'; although it dates from 1881, it is still impressive nowadays by the value and modernity of its ideas. The text is also important for the history of the Romanian linguistic terminology, as it includes concepts and the corresponding terms specific to that period (either borrowed and adapted to the internal inflectional patterns or created in Romanian). Hasdeu's texts are also impressive for the modernity of the linguistic terminology used.

From the point of view of the topics covered, the current issue includes articles dealing with morphology and the morphology-phonology interface: The perfective auxiliary $\mathrm{o}$ in the Moldavian variety. Diachrony and synchrony; Old Romanian pluralized mass and abstract nouns; Morphological instances of veri in old (Daco-)Romanian; The auxiliary of the Romanian conditional: semantic and functional argu-

\footnotetext{
*Email address: g_dindele@yahoo.com.
} 
ments concerning the reconstruction of a disputed grammaticalization process. Another three articles deal with syntax and the syntax-semantics relation: Some notes on the realizations of the direct object in the old language; Comparative constructions in old Romanian; (Pseudo)cleft constructions in old Romanian. For morpho-syntax, the following papers are relevant: Morphosyntactic features of the indefinite tot in old Romanian; Features of noun quantifiers in old Romanian; The descendants of Lat. ipse in Romanian. There is also one article on word formation and its relation to the inflectional morphology: The plural ending -le and influences between the inflectional and the derivational morphology. One of the articles deals with the domain of pragmatics and the grammar-pragmatics interface: The interjection in old Romanian texts.

It is important to note that the volume is rich and diverse. As a result of their research, the authors bring into discussion new descriptive observations (either general or more detailed), but also modifications in previous analyses, subtle remarks, or explanatory notes on previous interpretations, therefore worthy of the interest of the research community. 